\title{
GERMINAÇÃo DAS SEMENTES DE Conyza canadensis E Conyza bonariensis EM FUnÇÃo DA DISPONIBILIDADE HÍdRICA NO SUBSTRATO ${ }^{1}$
}

\author{
Germination of Conyza canadensis and Conyza bonariensis Seeds in Function of Water \\ Availability in the Substrate
}

\author{
YAMASHITA, O.M. ${ }^{2}$ e GUIMARÃES, S.C. ${ }^{3}$
}

\begin{abstract}
RESUMO - Recentes relatos apresentam Conyza canadensis e C. bonariensis como importantes espécies daninhas do sistema agrícola. A grande adaptabilidade ecológica dessas espécies a sistemas conservacionistas de manejo de solo e o aumento da pressão de seleção, pelo intenso uso de herbicidas, podem contribuir para a seleção de biótipos resistentes. O conhecimento dos fatores que controlam a germinação das sementes pode gerar subsídios para estratégias de manejo dessas espécies. A disponibilidade de água afeta diretamente a germinabilidade de sementes. Assim, o presente trabalho teve como objetivo estudar o efeito da restrição hídrica no substrato e seu efeito na germinação das sementes de Conyza canadensis e C. bonariensis. Foram realizados três ensaios no Laboratório de Sementes da Universidade do Estado de Mato Grosso, Campus Universitário de Alta Floresta-MT. No primeiro experimento, em caixas gerbox, foi estudado o comportamento germinativo das espécies segundo o arranjo fatorial $2 \times 6$, sendo duas espécies (Conyzacanadensis e C. bonariensis) e seis potenciais osmóticos $(0,0 ;-0,20 ;-0,40 ;-0,60 ;-0,80$; e $-1,00 \mathrm{MPa})$ proporcionados pela diluição em água de polietilenoglicol. No segundo experimento, também em arranjo fatorial $2 \times 6$, as espécies foram submetidas a menores potenciais osmóticos $(0,0 ;-0,05 ;-0,10 ;-0,15 ;-0,20 ;$ e $-0,30 \mathrm{MPa})$ em soluções de polietilenoglicol. No terceiro experimento, as sementes das espécies foram estudadas em esquema fatorial $2 \times 2 \times 5$, em que as duas espécies (C. canadensis e C. bonariensis) foram colocadas para germinar em dois substratos (solo de mata e areia), fornecendo-se água suficiente para atingir cinco capacidades de retenção de água (20, 40, 60, 80 e 100\%). Os resultados dos experimentos revelaram que a germinação total e a velocidade de germinação das sementes de Conyza foram reduzidas com a diminuição da disponibilidade hídrica no substrato, a partir de $-0,20 \mathrm{MPa}$. Água em excesso no substrato reduziu a emergência total e a velocidade de emergência das sementes das duas espécies de Conyza.
\end{abstract}

Palavras-chave: planta daninha, buva, voadeira, PEG 6000, potencial hídrico.

\begin{abstract}
Recent reports show Conyza canadensis and C. bonariensis as important weeds of the agricultural system. The great ecological adaptability of these species to conservationist soil management systems and the increased selection pressure caused by intense herbicide use may contribute to selection of resistant biotypes. Understanding the factors factors that control seed germination can supply the basis for the development of management strategies for these species. Water availability has a direct effect on seed germination capacity. Thus, this work aimed to study the effect of water restriction on the substrate and its effect on Conyza Canadensis and C. bonariensis seed germination. Three assays were carried out at the Seed Laboratory of the Universidade do Estado do Mato Grosso in Alta Floresta-MT Academic Campus. The first experiment using gearboxes studied the germinative behavior of the species, using the factorial scheme $2 \times 6$, with two species and six water potentials $(0.0 ;-0.20 ;-0.40 ;-0.60 ;-0.80$ and $-1.00 \mathrm{MPa})$ being
\end{abstract}

1 Recebido para publicação em 3.6.2009 e na forma revisada em 15.6.2010.

Parte da tee de Doutorado do primeiro autor apreentada à FAMEV/UFMT.

2 Eng-o-Agr ${ }^{\circ}$., D.Sc., Prof. do Dep. de Agronomia, Universidade do Estado de Mato Grosso - Campus Universitário de Alta Floresta, Caixa Postal 324, 78580-000 Alta Floresta-MT, <yama@unemat.br>; ${ }^{3}$ Eng-o-Agr ${ }^{\circ}$, D. Dc., Prof. FAMEV, Universidade Federal de Mato Grosso, Av. Fernando Corrêa da Costa s/n, 78060-900 Cuiabá-MT, <sheep@ufmt.br>.

Planta Daninha, Viçosa-MG, v. 28, n. 2, p. 309-317, 2010 
provided by diluting polyethylene glycol in water. In the second experiment, also in a factorial scheme $2 \times 6$, the species were submitted to lower water potentials $10.0 ;-0.05 ;-0.10 ;-0.15 ;-0.20$ and -0.30 MPa) in polyethylene glycol solutions. In the third experiment, the seeds were studied in a factorial scheme $2 \times 2 \times 5$, in which the two species germinated in two substrates (forest soil and sand), with sufficient water being supplied to reach five water retention capacities (20, 40, 60, 80 and $100 \%)$. The results of the experiments showed that total germination and germination speed of Conyza seeds were reduced by decreased water restriction in the substrate, starting from $-0.20 \mathrm{MPa}$. Excess water in the substrate reduced total emergence and emergence speed of Conyza seeds.

Keywords: weed, horseweed, fleabane, PEG 6000, water potential.

\section{INTRODUÇÃO}

As sementes são sujeitas a estresses que limitam o crescimento e o desenvolvimento de plantas, independentemente do ambiente de germinação (Baskin \& Baskin, 1998). Os fatores críticos no ambiente - água, oxigênio, luz, temperatura e substâncias químicas determinam quando e como a germinação acontece (Bewley \& Black, 1994).

A disponibilidade de água afeta diretamente a germinabilidade de sementes (Baskin \& Baskin, 1998; Marcos Filho, 2005). Esta participa de todas as etapas metabólicas, reações enzimáticas e digestão hidrolítica de proteínas, carboidratos e lipídios dos tecidos de reserva das sementes (Bewley \& Black, 1994; Carvalho \& Nakagawa, 2000).

A partir da absorção de água, ocorre a reidratação dos tecidos, com consequente intensificação da respiração e de todas as outras atividades metabólicas (Baskin \& Baskin, 1998; Marcos Filho, 2005). Na embebição da semente, a entrada de água para o interior dá-se exclusivamente por diferença de potencial hídrico entre o interior da semente e o exterior (meio em que ela se encontra) (Cardoso, 2004). O suprimento suficiente de água é fundamental para ativar a síntese proteica; assim, em condições naturais, a capacidade de sementes de algumas espécies germinarem sob condições de estresse hídrico confere a estas vantagens ecológicas (Carvalho $\&$ Cruz Filho, 1985).

A semente seca apresenta potencial hídrico muito baixo: em média, -200 MPa; logo, a limitação da embebição frequentemente está relacionada com a baixa disponibilidade de água no meio (Bewley \& Black, 1994).
Potenciais osmóticos muito negativos, principalmente no início da embebição, influenciam a absorção de água pelas sementes, podendo inviabilizar a sequência de eventos do processo germinativo (Bansal et al., 1980; Mikusinski, 1987).

O estresse hídrico geralmente atua diminuindo a velocidade e a porcentagem de germinação das sementes; para cada espécie existe um valor de potencial hídrico no solo, abaixo do qual a germinação não ocorre (Adegbuyi et al., 1981; Borges \& Rena, 1993). Por outro lado, o excesso de umidade no substrato pode ocasionar redução no percentual germinativo, por impedir a penetração do oxigênio e reduzir todo o processo metabólico resultante (Borges \& Rena, 1993).

Para simular condições de déficit hídrico, o PEG (polietilenoglicol) e manitol têm sido comumente utilizados em laboratório como agentes osmóticos, porque são compostos quimicamente inertes e não tóxicos (Thill et al., 1979; Braccini et al., 1996; Tambelini \& Perez, 1998).

Conyza canadensis e $C$. bonariensis são plantas daninhas que têm sua disseminação relatada em todo o mundo. A grande adaptabilidade ecológica dessas espécies a sistemas conservacionistas de manejo de solo e o aumento da pressão de seleção, pelo intenso uso de herbicidas, estão contribuindo para a seleção de biótipos resistentes dessas espécies. O conhecimento dos fatores que controlam a germinação das sementes pode gerar alternativas para futuras estratégias de manejo dessas espécies.

Com o objetivo de gerar subsídios para o manejo de Conyza canadensis e $C$. bonariensis, 
realizou-se o presente trabalho, que estudou a germinação das sementes em função da disponibilidade hídrica no substrato.

\section{MATERIAL E MÉTODOS}

Foram desenvolvidos três experimentos nas dependências do Laboratório de Sementes da UNEMAT, Campus Universitário de Alta Floresta, no município de Alta Floresta, MT, entre os meses de dezembro de 2007 e março de 2008.

Para os três experimentos, utilizou-se o delineamento experimental inteiramente casualizado, com quatro repetições. Os tratamentos foram arranjados em esquema fatorial.

As sementes de Conyza foram coletadas em outubro de 2007, de plantas daninhas em áreas de cultivo na região de Alta Floresta-MT. Os capítulos foram colhidos manualmente, quando as sementes estavam prontas para dispersão pelo vento, ou seja, quando agitadas, ocorria o seu desprendimento da inflorescência. Após a colheita, foram deixadas para secar à sombra. Foi realizada uma seleção visual, descartando-se as sementes com evidência de danos ou malformadas. As sementes selecionadas foram armazenadas em câmara refrigerada $\left(12,0 \pm 0,5{ }^{\circ} \mathrm{C}\right.$ e $75 \pm 2 \%$ umidade), até seu uso.

Para os experimentos em câmaras de germinação do tipo BOD, foram utilizadas como unidades experimentais caixas acrílicas transparentes do tipo gerbox $(11,0 \times 11,0$ x 3,5 cm). Estas foram limpas com água sanitária comercial (2,5\% de cloro ativo) diluída em água a $5 \%(\mathrm{v} / \mathrm{v})$ e, em seguida, borrifadas com álcool 70\% (v/v) e secas ao ar sobre bancada, em temperatura ambiente. Os papéis mata-borrão, utilizados como substratos, foram envolvidos em folhas de aluminio e esterilizados em autoclave a $120{ }^{\circ} \mathrm{C}$ por três horas. Quanto ao experimento em recipientes plásticos, estes foram limpos com flanela esterilizada, umedecida com água sanitária comercial (2,5\% de cloro ativo) diluída em água a $10 \%$ (v/v), e em seguida borrifados com álcool $70 \%(\mathrm{v} / \mathrm{v})$ e secos ao ar sobre bancada, em temperatura ambiente. Os substratos (solo de mata e areia) foram peneirados (peneira de
$2 \mathrm{~mm}$ ) e posteriormente autoclavados a $120{ }^{\circ} \mathrm{C}$ por cinco horas.

Foram realizados três ensaios para avaliar a germinação de sementes das espécies em condições de estresse osmótico.

No primeiro experimento, organizado em esquema fatorial $2 \times 6$, estudou-se a germinação de sementes das duas espécies (C. canadensis e C. bonariensis) sobre papel umedecido com soluções aquosas de polietilenoglicol (PEG 6000) com seis potenciais $(0,0 ;-0,20 ;-0,40 ;-0,60 ;-0,80 ; \mathbf{e}-1,00 \mathrm{MPa})$. As soluções foram preparadas com a dissolução de quantidade apropriada em água deionizada. O cálculo da quantidade de PEG 6000 para cada concentração foi obtido utilizando-se a equação proposta por Michel \& Kaufmann (1973). As sementes foram distribuídas nas caixas acrílicas, sobre as duas folhas de papel mataborrão, e colocadas para germinar em câmaras BOD reguladas para temperatura de $\pm 25^{\circ} \mathrm{C}$ e 12 horas de luz. Foram utilizadas quatro repetições de 50 sementes por gerbox. As caixas foram distribuídas de forma aleatória dentro da BOD (delineamento inteiramente casualizado). Os substratos eram trocados a cada quatro dias, sendo umedecidos da mesma forma. O volume de solução foi preparado na proporção suficiente para as substituições dos substratos até o final do experimento, sendo mantido em balões volumétricos lacrados dentro da mesma BOD dos tratamentos. Foram realizadas avaliações diárias, nas quais as sementes germinadas (radícula $\geq 2,00 \mathrm{~mm}$ ), após contadas, eram retiradas. As avaliações foram conduzidas por 20 dias. Após esse período, todos os tratamentos foram transferidos para substrato umedecido com água destilada, sendo realizada a contagem das sementes germinadas por mais 10 dias. A viabilidade das sementes não germinadas foi verificada por meio do teste da "pressão ao toque", com pinça, considerando-se como viáveis as sementes firmes (Isaac \& Guimarães, 2008).

Com base nos dados obtidos, foram calculados a germinação acumulada e germinação final (média da porcentagem de sementes germinadas de cada tratamento) e o índice de velocidade de germinação (IVG) (Maguire, 1962). Os dados obtidos não sofreram qualquer transformação e, após atenderem às 
pressuposições de normalidade e homocedasticidade, foram submetidos à análise de variância, e as médias foram comparadas pelo teste de Tukey a $5 \%$ de probabilidade, utilizando-se o programa de análises estatísticas SISVAR (Ferreira, 1999).

Após análise dos resultados obtidos no primeiro experimento, realizou-se um segundo, avaliando maiores potenciais osmóticos, sendo organizado em esquema fatorial $2 \times 6$. Estudou-se a germinação de sementes das duas espécies (C. canadensis e C. bonariensis) sobre papel umedecido com soluções aquosas de polietilenoglicol (PEG 6000) com seis potenciais: $0,-0,05 ;-0,10 ;-0,15 ;-0,20 ;$ e $-0,30 \mathrm{MPa}$. Para este ensaio, seguiram-se os mesmos procedimentos descritos anteriormente.

Realizou-se o terceiro experimento, avaliando a capacidade germinativa de sementes de Conyza em delineamento experimental em blocos ao acaso no esquema fatorial $2 \times 2 \times 5$, em que duas espécies (C. canadensis e $C$. bonariensis) foram colocadas para germinar em dois substratos (solo de mata e areia), fornecendo-se água suficiente para atingir cinco capacidades de retenção de água $(20$, 40, 60, 80 e 100\%), com quatro repetições. Foram utilizados recipientes plásticos com capacidade para $200 \mathrm{~mL}$, sendo cada um deles preenchido com os seguintes substratos: solo de mata (160 g) ou areia (200 g). A determinação da capacidade de retenção de água de cada substrato foi realizada colocando-se uma quantidade predefinida de água $(300 \mathrm{~mL}) \mathrm{em}$ copos perfurados e preenchidos com os substratos. Estes copos foram colocados sobre béquer, mantido suspenso por uma peneira. Após uma hora, com auxílio de proveta graduada, foi determinado o volume de água retido no béquer, sendo calculados os volumes de água necessárias para atingir cada capacidade de retenção (em \%). Foram semeadas 25 sementes em cada unidade experimental. Cada recipiente era colocado sobre balança semianalitica $(0,05 \mathrm{~g})$ e feito o fornecimento de água até a quantidade determinada para cada tratamento. A reposição de água era realizada diariamente no mesmo horário, com auxílio de uma seringa graduada munida de agulha com ponta dobrada, visando promover uma distribuição suave e uniforme da água. $O$ tratamento de $100 \%$ de capacidade de retenção de água foi mantido constantemente sob subirrigação, cujos recipientes foram mantidos dentro de bandeja plástica com água destilada. Acompanhou-se a temperatura e umidade através da leitura em termoigrômetro digital (HT 210 Instrutherm). Acompanhou-se a emergência de plântulas por 21 dias, sendo estas contadas e mantidas dentro de cada recipiente. Com base nos dados obtidos, foram calculados a emergência acumulada, a emergência final e o índice de velocidade de emergência (IVE) das sementes (Maguire, 1962). Os dados obtidos não sofreram qualquer transformação e, após atenderem às pressuposições de normalidade e homocedasticidade, foram submetidos à análise de variância, sendo as médias comparadas pelo teste de Tukey a $5 \%$ de probabilidade, utilizando-se o programa de análises estatísticas SISVAR (Ferreira, 1999).

\section{RESULTADOS E DISCUSSÃO}

No primeiro ensaio, quando foram testadas concentrações que variaram entre 0,2 e -1,0 MPa de PEG 6000, tanto para a variável germinação final (\%) como índice de velocidade de germinação (IVG), houve significância para espécie $(p<0,01)$ e potencial $(p<0,01)$, não havendo, entretanto, significância para a interação entre os fatores $(p>0,05)$ (Tabela 1).

Tanto a germinação como o IVG foram maiores para C. canadensis, caracterizando que essa espécie, nos potenciais estudados, mostrou-se mais tolerante à restrição hídrica que $C$. bonariensis.

Dos potenciais estudados, observou-se redução significativa da germinação e da velocidade germinativa já a partir de $-0,2 \mathrm{MPa}$, decrescendo para menos de $50 \%$ do percentual observado na testemunha quando as sementes foram colocadas para germinar em potencial de -0,4 MPa (Figura 1). A partir desse potencial, observou-se que praticamente não houve germinação de sementes de Conyza. Esses resultados concordam com os obtidos por Nandula et al. (2006), que observaram redução significativa na germinação de sementes de C. canadensis, mostrando que essa espécie é sensivel a baixos potenciais osmóticos $(<-0,2 \mathrm{MPa})$. 
Tabela 1 - Germinação total (\%) e IVG (índice de velocidade de germinação) de sementes de Conyza canadensis e C. bonariensis colocadas para germinar em substrato umedecido com concentrações decrescentes de PEG 6000 (polietilenoglicol). Alta Floresta-MT, 2008

\begin{tabular}{|c|c|c|}
\hline Espécie & $\begin{array}{c}\text { Germinação } \\
(\%)\end{array}$ & IVG \\
\hline Conyza canadensis & $32,17 \mathrm{~b}$ & $3,42 \mathrm{~b}$ \\
\hline Conyza bonariensis & $37,92 \mathrm{a}$ & $4,30 \mathrm{a}$ \\
\hline Valor de $\mathrm{F}$ & $5,88^{*}$ & $8,51^{*}$ \\
\hline \multicolumn{3}{|l|}{ Potencial (MPa) } \\
\hline 0,00 & $91,50 \mathrm{a}$ & $13,97 \mathrm{a}$ \\
\hline$-0,20$ & $76,00 \mathrm{~b}$ & $6,68 \mathrm{~b}$ \\
\hline$-0,40$ & $42,75 \mathrm{c}$ & $2,41 \mathrm{c}$ \\
\hline$-0,60$ & $0,01 \mathrm{~d}$ & $0,09 \mathrm{~d}$ \\
\hline$-0,80$ & $0,00 \mathrm{~d}$ & $0,01 \mathrm{~d}$ \\
\hline$-1,00$ & $0,00 \mathrm{~d}$ & $0,00 \mathrm{~d}$ \\
\hline Valor de $\mathrm{F}$ & $203,97 *$ & $225,13^{*}$ \\
\hline \multicolumn{3}{|c|}{ Interação (espécie x potencial) } \\
\hline Valor de F & $1,35^{\mathrm{ns}}$ & $1,91^{\text {ns }}$ \\
\hline $\mathrm{CV}(\%)$ & 23,45 & 27,29 \\
\hline
\end{tabular}

${ }^{\mathrm{ns}}$ não significativo pelo teste $\mathrm{F}$. $*$ significativo a $5 \%$ de probabilidade pelo teste $\mathrm{F}$

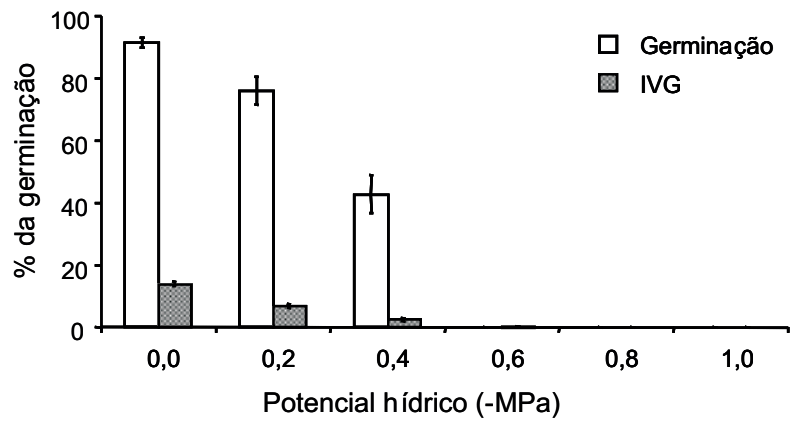

Figura 1 - Germinação total (\%) e IVG (índice de velocidade de germinação) de sementes de Conyza colocadas para germinar em substrato umedecido com concentrações decrescentes de PEG 6000 (polietilenoglicol). As barras representam erropadrão da média. Alta Floresta-MT, 2008.

Essa redução no percentual germinativo e no IVG à medida que o potencial osmótico se tornou mais negativo deve-se à redução na velocidade dos processos metabólicos e bioquímicos pela restrição hídrica, o que atrasa ou reduz a germinação das sementes e interfere na embebição e no elongamento celular do embrião (Bansal et al., 1980), além de reduzir ou impedir a emissão da raiz primária (Lopes et al., 1996), pela alteração da permeabilidade da membrana plasmática, e as propriedades do tonoplasto, aumentando a degradação de proteínas, por estimular a sintese de enzimas proteoliticas (Street \& Öpik, 1983).

No experimento realizado visando avaliar o efeito de maiores potenciais osmóticos (entre $-0,05$ e - 0,30 MPa), observou-se significância de espécie $(p<0,01)$ para a variável germinação final, de potencial $(\mathrm{p}<0,01)$ para ambas as variáveis e também para a interação entre os fatores $(\mathrm{p}<0,05)$ (Tabela 2).

Quanto à germinação total, não se observou diferença entre os potenciais para C. canadensis. Já para C. bonariensis, o potencial osmótico influenciou a germinação a partir de -0,05 MPa (Figura 2). Essa espécie mostrou-se mais sensivel à presença de restrição hídrica mesmo em baixos potenciais, discordando dos resultados descritos por Hanf (1983), que citou a tolerância de ambas as espécies à falta de água.

O estresse osmótico pode atuar de forma positiva no estabelecimento da espécie, pois provoca atraso no tempo de germinação das sementes; como estas são heterogêneas na sua resposta a esse estresse, a germinação é distribuída no tempo e no espaço, permitindo,

Tabela 2 - Germinação total (\%) e IVG (índice de velocidade de germinação) de sementes de Conyza canadensis e C. bonariensis colocadas para germinar em substrato umedecido com concentrações decrescentes de PEG 6000 (polietilenoglicol). Alta Floresta-MT, 2008

\begin{tabular}{|l|c|c|}
\hline Espécie & $\begin{array}{c}\text { Germinação } \\
(\%)\end{array}$ & IVG \\
\hline Conyza canadensis & 98,08 & 10,666 \\
\hline Conyza bonariensis & 85,00 & 10,304 \\
\hline Valor de F & $113,24^{*}$ & $1,23^{\text {ns }}$ \\
\hline Potencial (MPa) & & \\
\hline 0,00 & 98,75 & 13,49 \\
\hline$-0,05$ & 95,25 & 12,58 \\
\hline$-0,10$ & 92,50 & 10,58 \\
\hline$-0,15$ & 93,00 & 10,17 \\
\hline$-0,20$ & 89,75 & 9,18 \\
\hline$-0,30$ & 80,00 & 6,91 \\
\hline Valor de F & $18,10^{*}$ & $34,94^{*}$ \\
\hline Interação (espécie x potencial) & & \\
\hline Valor de F & $12,06^{*}$ & $5,28^{*}$ \\
\hline CV (\%) & 4,65 & 10,80 \\
\hline
\end{tabular}

${ }^{\mathrm{ns}}$ não significativo pelo teste $\mathrm{F} .{ }^{*}$ significativo a $5 \%$ de probabilidade pelo teste $\mathrm{F}$. 


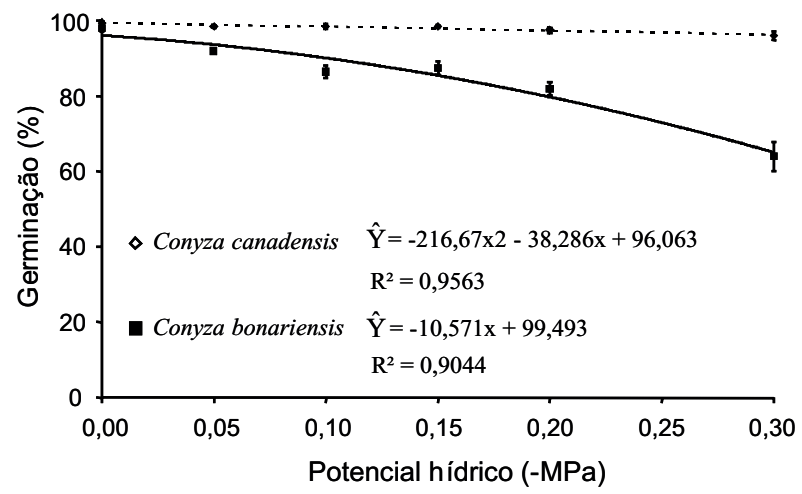

Figura 2 - Germinação total (\%) de sementes de Conyza colocadas para germinar em substrato umedecido com concentrações decrescentes de PEG 6000 (polietilenoglicol) As barras na vertical representam erro-padrão da média Alta Floresta-MT, 2008.

em condições naturais, aumento da probabilidade de plântulas encontrarem condições ambientais adequadas ao seu estabelecimento e desenvolvimento (Bewley \& Black, 1994; Nassif \& Perez, 1997). Apesar de a literatura descrever as espécies como plantas daninhas cuja distribuição é rara em regiões próximas à linha do Equador, a sua presença vem se intensificando em áreas de cultivo localizadas entre os trópicos (Lazaroto et al., 2008), sugerindo que elas possuem poucas limitações geográficas.

Quanto ao IVG, ambas as espécies mostraram-se sensiveis ao estresse osmótico do substrato, reduzindo a velocidade germinativa à medida que o potencial era diminuído (Figura 3).

Embora nem todas as espécies sejam influenciadas na mesma extensão (Sharma, 1973; Dias Filho, 1996; Grundy 1997), estudos sobre a germinação de sementes de plantas daninhas em diferentes potenciais osmóticos têm mostrado redução na germinação total e também na velocidade de germinação à medida que é reduzida a disponibilidade de água disponivel no substrato (Chachalis \& Reddy, 2000; Guimarães, 2000; Silva, 2008). Em trabalho desenvolvido por Nandula et al. (2006), C. canadensis mostrou-se sensivel à restrição hídrica, sugerindo que a falta de água no substrato poderia ser uma ameaça à planta daninha, sendo uma possivel forma de manejo dessa espécie.

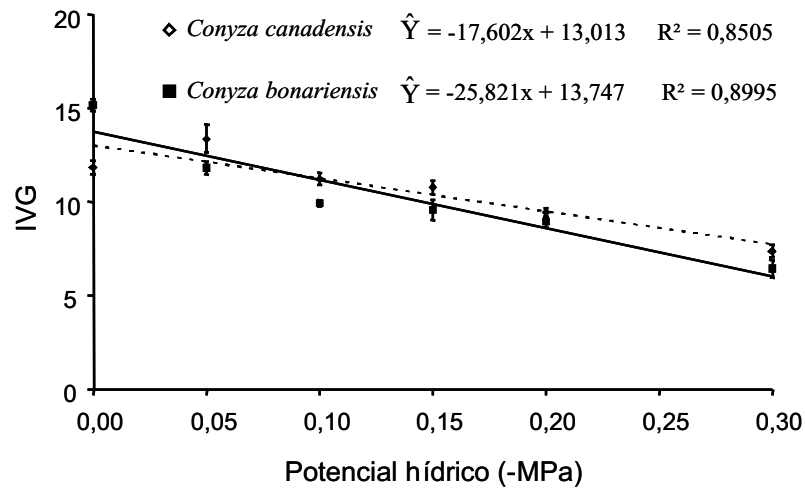

Figura 3 - Índice de velocidade de germinação de sementes de Conyza colocadas para germinar em substrato umedecido com concentrações decrescentes de PEG 6000 (polietilenoglicol). As barras na vertical representam erropadrão da média. Alta Floresta-MT, 2008.

Quando as sementes das espécies foram colocadas para germinar em solo e areia, com fornecimento controlado de água, para a variável emergência de plântula, houve significância para disponibilidade de água $(p<0,01)$ e para a interação entre espécie*disponibilidade $(\mathrm{p}<0,05)$ e substrato*disponibilidade $(p<0,01)$; para a variável IVE, houve significância para disponibilidade $(\mathrm{p}<0,01)$ e espécie*disponibilidade $(\mathrm{p}<0,05)$ (Tabela 3$)$.

A emergência total de ambas as espécies foi maior quando a disponibilidade de água foi de $80 \%$. Quanto à disponibilidade de água de $100 \%$, a emergência total, quando comparada à de $80 \%$, sofreu decréscimo próximo de $64 \%$ para ambas as espécies. Nas demais disponibilidades, a emergência não foi superior a $15,5 \%$ para $C$. canadensis e $7,0 \%$ para C. bonariensis (Tabela 4).

Esses resultados mostram que as espécies estudadas apresentam maior emergência quando a disponibilidade de água aproximase de $80 \%$, não tolerando áreas encharcadas ou com inundação do solo, o que concorda com informações descritas por Frankton \& Mulligan (1987) e Smith \& Moss (1998).

Em ambos os substratos estudados, a emergência foi maior na disponibilidade hídrica de $80 \%$, havendo forte redução quando o substrato estava inundado e emergência muito baixa para disponibilidade hídrica igual ou inferior a $60 \%$ (Tabela 5). 
Tabela 3 - Emergência total (\%) e IVE (índice de velocidade de emergência) de Conyza canadensis e C. bonariensis colocadas em diferentes substratos e quantidades de água disponível. Alta Floresta-MT, 2008

\begin{tabular}{|c|c|c|}
\hline Espécie (E) & $\begin{array}{c}\text { Emergência } \\
(\%)\end{array}$ & IVE \\
\hline Conyza canadensis & 27,00 & 1,33 \\
\hline Conyza bonariensis & 28,60 & 1,49 \\
\hline Valor de F & $0,66^{\text {ns }}$ & $1,17^{\text {ns }}$ \\
\hline Substrato (S) & & \\
\hline Solo de mata & 27,50 & 1,38 \\
\hline Areia & 28,10 & 1,44 \\
\hline Valor de F & $0,09^{\text {ns }}$ & $0,13^{\text {ns }}$ \\
\hline Disponibilidade de água (D) & & \\
\hline $20 \%$ & 0,00 & 0,00 \\
\hline $40 \%$ & 2,50 & 0,05 \\
\hline $60 \%$ & 11,25 & 0,45 \\
\hline $80 \%$ & 76,25 & 4,06 \\
\hline $100 \%$ & 49,00 & 2,49 \\
\hline Valor de F & $231,12^{*}$ & $108,61^{*}$ \\
\hline Interação (E x S) & & \\
\hline Valor de F & $2,32^{\text {ns }}$ & $3,95^{\text {ns }}$ \\
\hline Interação (E x D) & & \\
\hline Valor de F & $3,15^{*}$ & $2,42^{\text {ns }}$ \\
\hline
\end{tabular}

${ }^{\text {ns }}$ não significativo pelo teste $\mathrm{F}$. * significativo a $5 \%$ de probabilidade pelo teste $\mathrm{F}$.

Tabela 4 - Emergência total (\%) de Conyza canadensis e C. bonariensis colocadas em diferentes quantidades de água disponível. Alta Floresta-MT, 2008

\begin{tabular}{|c|c|c|}
\hline Disponibilidade & \multicolumn{2}{|c|}{ Espécie } \\
\cline { 2 - 3 } de água (\%) & Conyza canadensis & Conyza bonariensis \\
\hline 20 & $0,00 \mathrm{aD}$ & $0,00 \mathrm{aC}$ \\
\hline 40 & $3,50 \mathrm{aCD}$ & $1,50 \mathrm{aC}$ \\
\hline 60 & $15,50 \mathrm{aC}$ & $7,00 \mathrm{aC}$ \\
\hline 80 & $70,50 \mathrm{bA}$ & $82,00 \mathrm{aA}$ \\
\hline 100 & $45,50 \mathrm{aB}$ & $52,50 \mathrm{aB}$ \\
\hline $\mathrm{CV}(\%)$ & \multicolumn{2}{|c|}{31,69} \\
\hline
\end{tabular}

Médias seguidas de mesma letra, minúscula na linha e maiúscula na coluna, não diferem entre si pelo teste de Tukey a $5 \%$ de probabilidade.

Em areia, a manutenção da umidade é menor que em solo de mata, havendo secagem superficial do substrato mais rapidamente. Esse fato pode interferir no processo germinativo das sementes e, consequentemente, na emergência das plântulas. Áreas com solo mais arenoso e descoberto podem promover o rápido secamento dos primeiros centímetros do solo, interferindo na dinâmica populacional de plantas daninhas.

A não germinação de sementes em condições desfavoráveis, comum em plantas daninhas, pode ter significado ecológico, ligado à sobrevivência da espécie, pois previne o desenvolvimento de plântulas em solos sem os recursos suficientes para suportar o crescimento subsequente (Buhler et al., 1995; Vidal \& Bauman, 1996). Espécies cujas sementes não têm esse mecanismo de controle poderiam germinar todas ao mesmo tempo, após curto período de umedecimento do solo, comprometendo o desenvolvimento dos indivíduos formados e das futuras gerações (Guimarães et al., 2002; van den Berg \& Zeng, 2006; Silva, 2008).

O IVE, da mesma forma que a emergência total de plântulas, foi influenciado pela falta $\mathrm{e}$ pelo excesso de água no substrato para as

Tabela 5 - Emergência total (\%) de espécies de Conyza colocadas em diferentes quantidades de água disponível. Alta FlorestaMT, 2008

\begin{tabular}{|c|c|c|}
\hline Disponibilidade & \multicolumn{2}{|c|}{ Substrato } \\
\cline { 2 - 3 } de água (\%) & Solo de mata & Areia \\
\hline 20 & $0,00 \mathrm{aC}$ & $0,00 \mathrm{aD}$ \\
\hline 40 & $0,00 \mathrm{aC}$ & $5,00 \mathrm{aD}$ \\
\hline 60 & $0,00 \mathrm{bC}$ & $22,50 \mathrm{aC}$ \\
\hline 80 & $84,00 \mathrm{aA}$ & $68,50 \mathrm{bA}$ \\
\hline 100 & $53,50 \mathrm{aB}$ & $43,50 \mathrm{bB}$ \\
\hline $\mathrm{CV}(\%)$ & & 31,69 \\
\hline
\end{tabular}

Médias seguidas de mesma letra, minúscula na linha e maiúscula na coluna, não diferem entre si pelo teste de Tukey a $5 \%$ de probabilidade

Tabela 6-Índice de velocidade de emergência (IVE) de espécies de Conyza colocadas em diferentes quantidades de água disponível. Alta Floresta-MT, 2008

\begin{tabular}{|c|c|c|}
\hline Disponibilidade & \multicolumn{2}{|c|}{ Substrato } \\
\cline { 2 - 3 } de água (\%) & Solo de mata & Areia \\
\hline 20 & $0,00 \mathrm{aC}$ & $0,00 \mathrm{aC}$ \\
\hline 40 & $0,00 \mathrm{aC}$ & $0,11 \mathrm{aC}$ \\
\hline 60 & $0,00 \mathrm{bC}$ & $0,90 \mathrm{aC}$ \\
\hline 80 & $4,43 \mathrm{aA}$ & $3,68 \mathrm{bA}$ \\
\hline 100 & $2,48 \mathrm{aB}$ & $2,50 \mathrm{aB}$ \\
\hline $\mathrm{CV}(\%)$ & \multicolumn{2}{|c}{48,91} \\
\hline
\end{tabular}

Médias seguidas de mesma letra, minúscula na linha e maiúscula na coluna, não diferem entre si pelo teste de Tukey a $5 \%$ de probabilidade.

Planta Daninha, Viçosa-MG, v. 28, n. 2, p. 309-317, 2010 
espécies estudadas (Tabela 6). Esses resultados mostram que a velocidade de germinação foi muito sensível à restrição e ao excesso de água do substrato, concordando com resultados obtidos em Tridax procumbens por Guimarães (2000).

Com base nos resultados, conclui-se que a germinação total e a velocidade de germinação das sementes de Conyza são reduzidas com a diminuição da disponibilidade hídrica no substrato, a partir de $-0,15 \mathrm{MPa}$. Água em excesso reduz a emergência total e a velocidade de emergência das sementes de Conyza.

\section{LITERATURA CITADA}

ADEGBUYI, E.; COOPER, S. R.; DON, R. Osmotic priming of some herbage grass seed using polyethyleneglycol (PEG). Seed Sci. Technol., v. 9, n. 3, p. 867-878, 1981.

BANSAL, R. P.; BHATI, P. R.; SEN, D. N. Differential specificity in water inhibition of Indian arid zone. Biol. Plant, v. 22, n. 5, p. 327-331, 1980

BASKIN, C. C.; BASKIN, J. M. Seeds: ecology, biogeography, and evolution of dormancy and germination San Diego: Academic Press, 1998. 666 p.

BEWLEY, J. D.; BLACK, M. Seeds: physiology of development and germination. 2.ed. New York: Plenum, 1994. $445 \mathrm{p}$.

BORGES, E. E. L.; RENA, A. B. Germinação de sementes In: AGUIAR, I. B.; PIÑA-RODRIGUES, F. C. M.; FIGLIOLIA, M. B. Sementes florestais tropicais. Brasília: ABRATES, 1993. p. 83-135.

BRACCINI, A. L. et al. Germinação e vigor de sementes de soja sob estresse hídrico induzido por soluções de cloreto de sódio, manitol e polietilenoglicol. R. Bras. Sementes, v. 18, n. 2 , p. $10-16,1996$

BRADFORD, K. J. A. Water relations analysis of seed germination rates. Plant Physiol., v. 94, n. 3, p. 840-849, 1990.

BUHLER, D. D. et al.. Integrating mechanical weeding with reduced herbicide use in conservation tillage corn production systems. Agron. J., v. 87, n. 3, p. 507-512, 1995.

CARDOSO, V. J. M. Germinação. In: KERBAUY, G. B. (Ed.). Fisiologia vegetal. Rio de Janeiro: Guanabara Koogan, 2004. p. $386-408$.
CARVALHO, N. M.; NAKAGAWA, J. Sementes: ciência, tecnologia e produção. 4.ed. Campinas: Fundação Cargill, 2000. 588 p.

CARVALHO, M. M.; CRUZ FILHO, A. B

Estabelecimento de pastagem. Coronel Pacheco: EmbrapaCNPGL, 1985. 46 p. (Circular Técnica, 26).

CHACHALIS, D.; REDDY, K. N. Factors affeting Campis radicans seed germination and seedling emergence. Weed Sci., v. 48 , n. 2 , p. $212-216,2000$

DIAS FILHO, M. B. Germination and emergence of Stachytarpheta cayennensis and Ipomoea asarifolia. Planta Daninha, v. 14, n. 2, p. 118-126, 1996.

FERREIRA, D.F. Sistema de análise de variância (SISVAR). Versão 4.6. Lavras: Universidade Federal de Lavras, 1999. CD ROM.

FRANKTON, C.; MULLIGAN, G. A. Weeds of Canada (revised). Toronto: 1987. $217 \mathrm{p}$

GRUNDY, A. C. The influence of temperature and water potential on the germination of seven different dry-stored seed lots of Stellaria media. Weed Res., v. 37, n. 4, p. 257-266, 1997.

GUIMARÃES, S. C. Biologia da erva-de-touro (Tridax procumbens $\mathrm{L}$.): desenvolvimento, capacidade reprodutiva e germinação de sementes. 2000. 133 f. Tese (Doutorado em Fitotecnia) - Universidade Federal de Lavras, Lavras, 2000.

HANF, M. The arable weeds of Europe with their seedlings and seed. Ludwigshafen: BASF

Aktiengesellschaft, 1983. $494 \mathrm{p}$

ISAAC, R. A.; GUIMARÃES, S. C. Banco de sementes e flora emergente de plantas daninhas. Planta Daninha, v. 26, n. 3, p. 521-530, 2008.

LAZAROTO, C. A.; FLECK, N. G.; VIDAL, R. A. Biologia e ecofisiologia de buva (Conyza bonariensis e Conyza canadensis). Ci. Rural, v. 38, n. 3, p. 852-860, 2008

LOPES, H. M. et al. Influência do potencial osmótico e da temperatura na embebição e no crescimento da radícula de sementes de cebola (Allium cepa L.). R. Bras. Sementes, v. 18 , n. 2, p. $167-172,1996$

MAGUIRE, J. D. Speed of germination-aid in relation evaluation for seedling emergence vigor. Crop Sci., v. 2, n. 2 , p. 176-177, 1962.

MARCOS FILHO, J. Germinação. In: MARCOS FILHO, J. Fisiologia de sementes de plantas cultivadas. Piracicaba: FEALQ, 2005. p. 197-252. 
MICHEL, B. E.; KAUFMANN, M. R. The osmotic potential of polyethilene glycoI 6000. Plant Physiol., v. 51, n. 6, p. 914-916, 1973.

MIKUSINSKI, O. M. Testes de embebição e germinação em sementes de Ipomoea aristolochiaefolia. R. Bras. Sementes, v. 9 , n. 3, p. 103-108, 1987.

NANDULA, V. K. et al. Factors affecting germination of horseweed (Conyza canadensis). Weed Sci., v. 54, n. 5, p. 898-902, 2006.

NASSIF, S. M. L.; PEREZ, S. C. J. G. A. Germinação de sementes de amendoim do campo (Pterogynes nitens Tul. Fabaceae-Caesalpinoideae) submetidas a diferentes condições de estresse hídrico e salino. R. Bras. Sementes, v. 19, n. 2 , p. 142-149, 1997.

SHARMA, M. L. Simulation of drought and its effect on germination of five pasture species. Agron. J., v. 65, n. 6, p. 982-987, 1973.

SILVA, J. L. Germinabilidade de sementes de Chloris barbata (L.) Sw. 2008. 72 f. Dissertação (Mestrado em Agricultura Tropical) - Universidade Federal de Mato Grosso, Cuiabá, 2008
SMITH, M.; MOSS, J. S. An experimental investigation, using stomatal conductance and fluorescence, of the flood sensitivity of Boltonia decurrens and its competitors.

J. Appl. Ecol., v. 35, n. 4, p. 553-561, 1998.

STREET, H. E.; ÖPIK, H. The physiology of flowering plants, their growth and development. Maryland: Edward Arnold, 1983. 279 p.

TAMBELINI, M.; PEREZ, S. C. J. G. Efeitos do estresse hídrico simulado com peg (6000) ou manitol na germinação de sementes de barbatimão (Stryphnodendron polyphyllum Mart.). R. Bras. Sementes, v. 20, n. 1, p. 226-232, 1998.

THILL, D. C.; SCHIMMAN, R. D.; APPLEBY, A. P. Osmotic stability of mannitol and polyethyleneglycol 20000 solutions used as seed germination media. Agron. J., v. 71, n. 1, p. 105-108, 1979.

Van den BERG, L.; ZENG, Y. J. Response of South African indigenous grass species to drought stress induced by polyethylene glycol (PEG) 6000. S. Afr. J. Bot., v. 72, n. 2, p. 284-286, 2006.

VIDAL, R. A.; BAUMAN, T. T. Surface wheat (Triticum aestivum) residues, giant foxtail (Setaria faberi), and soybean (Glycine max) yield. Weed Sci., v. 44, n. 4, p. 939-943, 1996. 